\title{
(IN)EQUIDADE DE GÊNERO E ENSINO JURÍDICO: O PAPEL DA PÓS- GRADUAÇÃO PARA A REPRESENTAÇÃO FEMININA NO DIREITO
}

\author{
Ana Elisa Liberatore S. Bechara ${ }^{I}$
}

\begin{abstract}
"La historia nos demuestra que es más fácil aplaudir
a algunas 'grandes' mujeres, que cuestionar y confrontar la misoginia que penetra el Derecho".
\end{abstract}

Introdução

As mulheres que atualmente compõem o corpo docente nos cursos de Direito, egressas dos Programas de Pós-Graduação, fazem parte de gerações que sofreram e sofrem com estereótipos de gênero e as mais variadas formas de violência na esfera acadêmica, no âmbito de dinâmicas socioculturais até pouco tempo invisíveis e, por isso, pouco debatidas. Embora possam ser consideradas à primeira vista como vitoriosas e bem-sucedidas, essas docentes na verdade alcançaram as respectivas posições apesar do sistema. A par das tantas dificuldades individuais vivenciadas na trajetória acadêmica, é fundamental refletir, sob uma perspectiva mais abrangente, sobre os problemas do Direito como um território ainda masculino e, assim, sobre a importância e desafios da equidade de gênero no ensino jurídico.

A constatação das desigualdades de gênero na Academia, (re)produzidas em grande medida no campo simbólico (aquilo que se pensa sobre o que homens e mulheres são, devem e podem fazer em suas vidas profissionais e familiares), ${ }^{3}$ desconstrói o mito da meritocracia e revela a existência de uma barreira não apenas ao ingresso e à ascensão das mulheres, como também ao simples pertencimento ao espaço acadêmico. ${ }^{4}$ Como reflexo desse quadro de invisibilização de gênero e de naturalização do masculino, tem-se o enfraquecimento da pluralidade e, assim, da própria essência da Universidade.

Professora Titular de Direito Penal da Faculdade de Direito da Universidade de São Paulo, atualmente no exercício da Vice-Presidência da Comissão de Pós-Graduação da Faculdade (2018-2022).

2 FACIO, Alda. Hacia outra teoria crítica del derecho. In FACIO, A.; FRIES, Lorena (coord.). Género y derecho. Santiago de Chile: LOM Ediciones, 1999, p. 204.

3 Nesse sentido, v. MOSCHKOVICH, Marília Bárbara Fernandes Garcia. Teto de vidro ou paredes de fogo? Um estudo sobre gênero na carreira acadêmica e o caso da UNICAMP. 2013. Dissertação de Mestrado Universidade Estadual de Campinas, Faculdade de Educação, Campinas, SP, p. 111-112. Disponível em: http://www.repositorio.unicamp.br/REPOSIP/251113. Acesso em: 25 mar. 2021.

4 Cf. CAMPOS, Isabelle Oglouyan de. Mulheres na Academia: Desigualdades de Gênero no Corpo Docente da Faculdade de Direito da Universidade de São Paulo. São Paulo: Cátedra UNESCO de Direito à Educação/Universidade de São Paulo, 2021, p. 21-22. Disponível em: https://unesdoc.unesco.org/ ark:/48223/pf0000376046. Acesso em: 24 mar. 2021. 
Para além dos muros da Academia, a inequidade de gênero afeta diretamente as formas de produção e de aplicação do Direito, cristalizando-se em uma hegemonia discursiva que normaliza e reforça a cultura patriarcal e machista presente na sociedade. Justamente por isso, verifica-se ainda hoje no Direito brasileiro não apenas a reprodução, como também a construção de estereótipos de gênero que acabam por negar os direitos das mulheres, tornando-as mais vulneráveis à violência. ${ }^{5}$

Diante de tal cenário, é preciso refletir sobre o papel desempenhado pela Pós-Graduação, como locus de formação dos formadores, no processo de reconstrução do ensino jurídico sob a perspectiva da equidade de gênero e, consequentemente, na elaboração de mecanismos para a superação dos estereótipos e preconceitos sobre as mulheres que permeiam o universo jurídico.

1. Inequidade de gênero como base de um Direito desigual

A inequidade de gênero ${ }^{6}$ é uma característica da sociedade brasileira, sujeitando as mulheres a inúmeros tipos de violência, inclusive nos espaços universitários. Nesse contexto, para além das modalidades explícitas de agressão física e moral a que em geral são submetidas, em um nível talvez menos visível as mulheres são estereotipadas ${ }^{7}$ e silenciadas em sua capacidade intelectual, possuem baixa representação nos espaços institucionais de decisão, têm em geral uma carga horária maior de trabalho e recebem remuneração menor do que a recebida pelos homens. Daí afirmar-se que em suas inúmeras roupagens, a opressão de gênero possui um caráter estrutural, perpassando as mais diversas esferas, e atinge as mulheres de distintas maneiras, conforme marcadores

Tratando dos estereótipos de gênero nos crimes sexuais, v. PIMENTEL, Silvia; SCHRITZMEYER, Ana Lúcia P.; PANDJIARJIAN, Valéria. Estupro: crime ou "cortesia"? Abordagem sociojurídica de gênero. Porto Alegre: Fabris, 1998.

6 Desenvolvido sob diversas perspectivas teóricas feministas em contraposição à noção de sexo (que atribui um caráter natural ou biológico à diferença nas relações entre homens e mulheres), o conceito de gênero afirma o caráter social da construção dessa diferença, tomando-a como relacional e historicamente situada. Sobre o tema, v. SCOTT, Joan W. Gênero: uma categoria útil de análise histórica. Trad. Guacira Lopes Louro, revisão Tomaz Tadeu da Silva. Educação \& Realidade. Porto Alegre, v. 20, n. 2, jul./dez. 1995.

7 Sobre os estereótipos de gênero em ambiente acadêmico, e evidenciando que nessa esfera as mulheres acabam sendo valoradas e referidas mais por características pessoais de personalidade e aparência do que por aspectos de competência técnico-científica, v. BOKEK-COHEN, Ya'arit; DAVIDOWITZ, Nitza. Beauty and teaching evaluation: a comparison between female and male college professors. Problems of Education in the 21st Century, v. 7, 2008, p. 15 et seq. Disponível em: http://www.scientiasocialis.lt/ pec/files/pdf/Bokek-Cohen.pdf, e WU, Alice. Gender Stereotype in Academia: Evidence from Economics Job Market Rumors Forum, Working Papers 2017-09, Princeton University, Woodrow Wilson School of Public and International Affairs, Center for Health and Wellbeing, 2017. Disponível em: https://ideas. repec.org/p/pri/cheawb/2017-09.html. 
sociais de diferença que se intercomunicam, tais como raça, classe, orientação sexual e religião, no âmbito da denominada interseccionalidade. ${ }^{8}$

No universo específico do Direito, embora as mulheres representem cerca de metade do 1,2 milhão de inscritos na Ordem dos Advogados do Brasil, ${ }^{9}$ sua presença em cargos de liderança em carreiras do direito público e privado ainda é minoritária, se comparada à participação masculina. Assim, por exemplo, conforme os dados do Censo do Poder Judiciário, divulgado pelo Conselho Nacional de Justiça em 2014, ${ }^{10}$ embora mais da metade da população brasileira seja composta por mulheres, essas representam apenas $35,9 \%$ dos membros da magistratura, percentual este que diminui progressivamente conforme a ascensão aos cargos mais altos do Poder Judiciário: as mulheres correspondem a $36,6 \%$ dos juízes titulares, $21,5 \%$ dos desembargadores e somente a $18,4 \%$ dos ministros de tribunais superiores.

A partir do exemplo paradigmático da magistratura, observa-se em geral que, na medida em que as carreiras jurídicas progridem, a participação feminina diminui. De outro lado, nos distintos cenários profissionais é possível identificar uma tendência das mulheres de se espelharem no modelo masculino, ${ }^{11}$ levando ao apagamento de gênero e à consideração de uma suposta neutralidade do Direito, com consequências diretas para a aplicação deste à realidade social.

A esta altura, deve-se já advertir para uma questão central no debate sobre o ensino jurídico em si e, em especial, sobre as questões de gênero a ele vinculadas, referente à relação entre Direito e transformação social: soa paradoxal pensar no Direito como mecanismo útil para superar a cultura patriarcal machista e promover equidade de gênero, quando tradicionalmente esse instrumento de controle social formal tem servido

8 Nesse sentido, conforme Kimberlé Williams CRENSHAW, a interseccionalidade trata-se de uma forma de compreensão do problema: "que busca capturar as consequências estruturais e dinâmicas da interação entre dois ou mais eixos da subordinação. Ela trata especificamente da forma pela qual o racismo, o patriarcalismo, a opressão de classe e outros sistemas discriminatórios criam desigualdades básicas que estruturam posições relativas de mulheres, raças, etnias, classes e outras. Além disso, a interseccionalidade trata da forma como ações e políticas especificas geram opressões que fluem ao longo de tais eixos, constituindo aspectos dinâmicos ou ativos do desempoderamento". CRENSHAW, Kimberlé Williams. Documento para o encontro de especialistas em aspectos da discriminação racial relativos ao gênero. Estudos feministas, Ano 10, $1^{\circ}$ semestre de 2002, p. 177.

9 Informação disponível em: https://www.oab.org.br/institucionalconselhofederal/quadroadvogados. Acesso em: 30 mar. 2021.

10 Informação disponível em: https://www.cnj.jus.br/wp-content/uploads/2011/02/CensoJudiciario.final.pdf. p. 38. Acesso em: 29 mar. 2021.

11 Sobre a incorporação do modelo masculino pelas mulheres que conseguem superar o "teto de vidro", em especial na advocacia, v. BERTOLIN, Patrícia Tuma Martins. Feminização da advocacia e ascensão das mulheres nas sociedades de advogados. Cadernos de Pesquisa. 2017, v. 47, n. 163, p. 25. Disponível em: https://www.scielo.br/scielo.php?pid=S0100-15742017000100016\&script=sci_abstract\&tlng=pt. Acesso em: 2 abr. 2021. 
à dominação e opressão social. De fato, é preciso admitir que o sexismo é constitutivo do Direito, e não um mero desvio disfuncional. ${ }^{12}$

Dessa forma, embora nas últimas décadas os movimentos feministas tenham logrado importantes conquistas quanto à ratificação de documentos internacionais (tais como a Convenção para a Eliminação de Todas as Formas de Discriminação Contra a Mulher - CEDAW - e da Convenção de Belém do Pará) e à elaboração de diplomas normativos de Direito interno (a exemplo da emblemática Lei Maria da Penha e da Lei do Feminicídio), as mulheres seguem com a consciência de que provavelmente não serão tratadas com justiça na prática legal cotidiana. Isso porque, apesar da existência de direitos e garantias positivados, sua aplicação envolve, antes de mais nada, a linguagem e, a partir do reconhecimento de que o Direito materializa sempre um discurso de poder, a interpretação e aplicação das normas não está imune a disputas, cujo desfecho é necessariamente condicionado pela cultural patriarcal que permeia a sociedade.

Nesse sentido, observa de forma impactante Iáris Ramalho Cortês:

Durante a faculdade de Direito, sinceramente, eu não percebia as disparidades no conteúdo das leis e a discriminação; não percebia o que estava diante dos meus olhos, nos livros e na fala dos professores. Na época, não havia nenhuma professora, e menos de 5\% de alunas eram mulheres. Diziase que o Direito vem principalmente das tradições culturais e políticas do Direito Romano e é unificado pelo surgimento do Estado. Eu acreditava nessa afirmação, sem ver que esse Direito tinha uma concepção conservadora e patriarcal de família, na qual a mulher pertencia a uma categoria subalterna. (...) Ao ser convidada para trabalhar no Conselho Nacional de Direitos das Mulheres, em 1985, nunca imaginei que todos os meus antigos conceitos iriam ruir por terra, e que a expressão constitucional que afirmava 'igualdade de todos perante a lei' estava longe de ser verdadeira na vida real das mulheres. ${ }^{13}$

Assim, entre o dito (nos âmbitos legislativo e doutrinário) e o não-dito (nas manifestações formais dos distintos atores no processo de aplicação do Direito), a inequidade de gênero cristaliza-se como um fenômeno naturalizado, em um sistema jurídico ainda orientado por preconceitos e estereótipos intoleráveis em pleno Estado Democrático de Direito. ${ }^{14}$ Isso explica em grande medida o fato de que, a despeito da

12 No mesmo sentido, v. FACIO, Alda. Hacia otra teoría crítica del derecho, cit., p. 204.

13 PIMENTEL, Silvia et al. Recuperando a memória: a atuação das feministas na conquista dos direitos das mulheres e os desafios atuais para assegurar os direitos conquistados. In: Vv. Aa. Tecendo fios das críticas feministas ao direito no Brasil. Rev. Técnica Fabiana Severi e Myllena Calasans de Matos. Ribeirão Preto: FDRP/USP, 2019, p. 114-115.

14 No mesmo sentido, tratando especificamente da denominada "cultura do estupro", v. ANDRADE, Mailô 
promoção crescente de leis contra as distintas formas de violência de gênero, tal violência não tenha de fato diminuído na sociedade brasileira. ${ }^{15}$

Por isso, para além da necessidade de análise das manifestações de inequidade de gênero no próprio ensino jurídico, a condicionar a formação dos detentores do poder no campo do Direito, conforme será visto no tópico seguinte, faz-se necessário pensar também em uma teoria crítica do Direito, a partir de bases feministas. ${ }^{16}$

Se, atualmente, o pensamento crítico feminista parece surgir como novidade no campo acadêmico e se impor como uma tendência teórica inovadora com especial potencial crítico, isso é resultado de um percurso realizado desde os anos 1970 por diversas juristas feministas pioneiras, conforme atestam Fabiana Cristina Severi e Carmen Hein de Campos. ${ }^{17}$ As autoras precursoras do uso da abordagem feminista do direito no Brasil têm suas análises construídas tanto a partir do meio acadêmico quanto do contexto das estratégias de ação política feminista e, ao invés da disputa no campo da teoria do Direito ou da epistemologia jurídica, historicamente privilegiaram a elaboração de análises críticas a instituições específicas do Direito e sobre o uso estratégico do discurso jurídico. ${ }^{18}$

Embora na atualidade a maioria das autoras seja composta por pesquisadoras ou docentes formalmente vinculadas a cursos jurídicos ou a grupos de pesquisa em Direito, conferindo-lhes maior legitimidade de discurso no campo jurídico, ainda há uma resistência à incorporação das reflexões críticas feministas à teoria do Direito, marcada pela produção e lugar de fala masculinas.

Conforme observa Alda Facio, uma teoria crítica do Direito deve voltarse a uma transformação radical de perspectiva sobre o fenômeno jurídico, vinculando o Direito aos processos histórico-sociais em permanente evolução. Nesse sentido, é forçoso reconhecer que diversas das denominadas teorias críticas acabaram por incidir no mesmo equívoco das teorias tradicionais, no que se refere à equidade de gênero, por ocultarem as dificuldades e demandas das mulheres na sociedade. Então, para que uma teoria logre transformar realmente o Direito sob a perspectiva de gênero, deve provocar a

de Menezes Vieira. Ela não mereceu ser estuprada. A cultura do estupro nos casos penais. Rio de Janeiro: Lumen Juris, 2018, p. 173.

15 Nesse sentido, o Brasil ocupa a $5^{\text {a }}$ posição no Ranking Mundial sobre a morte violenta de mulheres (feminicídio), segundo o Alto Comissariado das Nações Unidas pra os Direitos Humanos (ACNUDH).

16 Não se pretendeu no presente artigo aprofundar as diversas teorias feministas e seus respectivos marcos, optando-se por considerar que todas as correntes do feminismo buscam algum grau de transformação do status jurídico e social das mulheres e, assim, necessariamente pretendem transformar as relações de poder entre os gêneros, o que levaria a transformar a própria estrutura da sociedade e do pensamento.

17 Cf. SEVERI, Fabiana Cristina; CAMPOS, Carmen Hein. Violence against women and the feminist critique of law: a brief analysis of Brazilian academic production. Revista Direito e Práxis, Rio de Janeiro, v. 10, n. 2, 2019, p. 966 et seq.

18 Idem, ibidem. 
reconstrução de conceitos pretensamente neutros, demonstrando sua base androcêntrica, com o fim de tornar visíveis as relações de poder e dominação que ocultam. ${ }^{19}$

Uma teoria que não admita que o Direito historicamente desempenhou um papel importante na manutenção e reprodução das diversas formas de desigualdade de gênero não pode ser considerada realmente crítica, justamente por não tomar em consideração as reflexões e conquistas dos movimentos feministas. ${ }^{20}$ Portanto, para que a sociedade seja mais igual e justa nas relações de gênero, faz-se necessário promover reflexões teóricas que levem a questionar por que o sujeito do Direito é o homem branco, heterossexual, com situação econômica favorável e sem incapacidades visíveis. E tal desenvolvimento teórico só será possível num contexto de um ensino jurídico sensível às questões de gênero.

Repensar o ensino jurídico não se resume, porém, a incluir no currículo das Universidades disciplinas sobre feminismo, devendo-se incentivar a reflexão sobre a própria situação acadêmica das mulheres, sua discriminação nos tribunais e a desvalorização das experiências pessoais como fonte de conhecimento, em prol de uma posição pretensamente objetiva e neutra da academia e do Direito. ${ }^{21}$ Trata-se, então, também de criar ambientes participativos que permitam a livre atuação das mulheres, por meio da própria reforma dos métodos tradicionais e conservadores de ensino e do incentivo à maior presença feminina, inclusive nos espaços de poder e tomada de decisões.

2. As interações de gênero no âmbito da Pós-Graduação e seus reflexos no ensino jurídico

A Pós-Graduação no Brasil passa por um marcado processo de expansão, seguindo uma já estabelecida tendência internacional. Porém, a despeito do expressivo crescimento do número de mestres e doutores titulados, e mesmo no âmbito de um Estado Democrático de Direito fundado na igualdade e no pluralismo político, os Programas de Pós-Graduação no país ainda são caracterizados por intensas desigualdades regionais, étnico-raciais, econômicas e de gênero, demandado uma especial reflexão sobre questões

\footnotetext{
Cf. FACIO, Alda. Hacia otra teoría crítica del derecho, cit., p. 206.

Idem, ibidem.

Cf. LEMAITRE RIPOLL, Julieta. El feminismo en la enseñanza del derecho en los Estados Unidos: estrategias para América Latina. Academia: Revista sobre enseñanza del Derecho de Buenos Aires, Buenos Aires, ano 3, n. 6, 2005, p. 177-178. Disponível em: https://revistas-colaboracion.juridicas.unam.mx/ index.php/revista-ensenianza-derecho/article/view/33855. Acesso em: 15 mar. 2021. Em igual sentido, v. MACKINNON, Catherine A. Mainstreaming feminism in legal education. Journal of Legal Education, v. 53, n. 2, 2003, p. 199 et seq., e ALMEIDA, Maria Clara D’Avila. Gênero, violência e subversão: o ensino jurídico como prática de liberdade. Trabalho de Conclusão de Curso, Faculdade de Ciências Jurídicas e Sociais do Centro Universitário de Brasília - UniCEUB. Brasília, 2016, p. 44-46.
} 
relacionadas à equidade no acesso, que ganham espaço na agenda política. A noção de equidade nessa esfera diz respeito principalmente à igualdade de oportunidades, o que significa que o acesso à Pós-Graduação deve depender apenas das habilidades e do esforço individual de cada um, não podendo fatores pessoais ou socioeconômicos constituir obstáculo ou vantagem na seleção, permanência e êxito em uma instituição de ensino.

Nesse contexto, a partir do fim da primeira década do presente século, diversos Programas de Pós-Graduação de Universidades públicas brasileiras começaram a instituir políticas de ações afirmativas voltadas a alunos de grupos vulnerabilizados, visando a inserir sujeitos historicamente excluídos do espaço acadêmico e, assim, a contribuir para a construção de ambientes mais plurais. ${ }^{22} \mathrm{O}$ objetivo de tais ações afirmativas vai além da consecução de um tratamento mais justo nos casos individuais para abranger benefícios à qualidade da pesquisa, à formação de futuros docentes e, assim, ao próprio aprimoramento da ciência.

Dentre as distintas formas de discriminação e desigualdade na PósGraduação, chama especial atenção a inequidade de gênero, em razão de sua pouca visibilidade e, assim, da menor consciência geral sobre as consequências negativas que é capaz de acarretar, gerando especiais desafios relacionados a estratégias de enfrentamento.

Se historicamente o ingresso feminino no corpo discente dos cursos de Pós-Graduação em Direito cresceu a ponto de corresponder na atualidade à metade do alunado, o mesmo não se verifica na composição docente, predominantemente masculina, branca, heterossexual, pertencente a classes sociais privilegiadas e ainda apoiada no ideário da neutralidade do conhecimento, construído sob base eurocêntrica. ${ }^{23} \mathrm{~A}$ questão fundamental é saber por que ocorre esse "desaparecimento" das mulheres durante a trajetória acadêmica e, a partir daí, estabelecer mecanismos de reequilíbrio de gênero.

Tratando especificamente dos dados referentes à Universidade de São Paulo (USP), conforme relatório divulgado pela ONU Mulheres, verifica-se que em 2015 as mulheres constituíam 46,4\% do corpo discente da graduação; $51,5 \%$ do corpo discente da pós-graduação; e 40,9\% do corpo docente com dedicação exclusiva. Referido relatório apontou, porém, que apenas $23,7 \%$ dos postos de senior leadership (cargos de reitor da Universidade, vice-reitor, decanos, diretores de ensino e pesquisa, diretores das faculdades e superintendentes) e 15,4\% dos cargos de professor titular eram ocupados

22 Sobre a evolução da adoção de ações afirmativas pelos Programas de Pós-Graduação das Universidades brasileiras, v. VENTURINI, Anna Carolina. Ações afirmativas para pós-graduação: desenho e desafios da política pública. $41^{\circ}$ Encontro Anual da ANPOCS, 2017.

23 Sobre o tema, v. BONELLI, Maria da Gloria. Docência do direito: fragmentação institucional, gênero e interseccionalidade. Cadernos de Pesquisa. 2017, v. 47, n. 163, p. 94 et seq. 
por mulheres, desenhando-se um cenário no qual o padrão do sujeito cognoscente e detentor do poder de decisão ainda é masculino. ${ }^{24}$

Ao trazer a análise de dados ao campo específico da Faculdade de Direito da USP, a inequidade de gênero resta ainda mais paradigmática: atualmente apenas 17\% do corpo docente, tanto na Graduação quanto na Pós-Graduação, é formado por mulheres e, tratando do nível mais alto da carreira, tal percentual cai para $11 \%$. Correspondendo à maioria absoluta, os homens (brancos ou embranquecidos pela posição social) ${ }^{25}$ detêm o protagonismo também na simbologia da Academia (seus nomes são os que identificam as salas de aula; suas imagens estão reproduzidas nos quadros que adornam o ambiente, sempre em homenagem ao masculino), de modo a afastar as mulheres de qualquer posição de poder e de espaços de convivência igual. O Direito é masculino, os métodos de ensino são masculinos e, como resultado, as mulheres acabam excluídas. Há, portanto, uma desigualdade estrutural de gênero que caracteriza o universo acadêmico, ainda que a atual gestão venha se esforçando de forma louvável para a adoção de medidas de afirmação e reconhecimento das docentes.

Dentre os fatores da baixa representatividade das mulheres na carreira docente, destaca-se o formato e dinâmica dos concursos de ingresso. Sob essa perspectiva, analisando-se os concursos públicos docentes na Faculdade de Direito da USP entre os anos de 2008 e 2017, verifica-se que os homens representaram 77\% dos candidatos, sem crescimento do número de mulheres inscritas. Da mesma forma, nos 145 concursos de ingresso, livre-docência e titularidade realizados nesse período, apenas $13 \%$ dos membros das bancas examinadoras eram mulheres. ${ }^{26}$

Evidente que, a partir do século XX, houve na história da Faculdade de Direito do Largo de São Francisco docentes mulheres com trajetória emblemáticas. Assim, a título ilustrativo, podem ser mencionadas as professoras Esther de Figueiredo Ferraz (primeira mulher a tornar-se professora da Faculdade de Direito, em 1948); Nair Lemos Gonçalves (primeira docente mulher a atingir a titularidade, em 1970); Eunice Aparecida de Jesus Prudente (primeira e única docente negra da Faculdade de Direito); Ivette Senise Ferreira (primeira e única diretora da Faculdade de Direito em 1998); e Ada Pellegrini Grinover (única docente mulher da Faculdade a exercer o cargo de Pró-Reitora - de Graduação - da USP). Diante da excepcionalidade das trajetórias nota-se, porém,

24 Cf. dados do Impact 10x10x10 University Parity Report 2016, elaborado pela ONU - Mulheres, p. 24.

25 Sobre o preenchimento das carreiras jurídicas e da docência acadêmica principalmente por homens, desde a criação dos cursos de Direito no Brasil, no século XIX, até a última década do século XX, v. ADORNO, Sérgio. Os aprendizes do poder. São Paulo: Paz e Terra, 1988, e VENÂNCIO FILHO, Alberto. Das arcadas ao bacharelismo: cento e cinquenta anos de ensino jurídico no Brasil. Rio de Janeiro: Perspectiva, 1977.

26 Conforme dados expostos na pesquisa de CAMPOS, Isabelle Oglouyan de. Mulheres na Academia, cit., p. 29 et seq. 
que as conquistas históricas de tais mulheres na verdade confirmam a regra de domínio masculino no espaço universitário. ${ }^{27}$ Em resumo, mencionadas docentes fizeram história na Academia apesar da estrutura patriarcal e machista do sistema.

A baixa representatividade de mulheres no espaço acadêmico tende a impactar a formação de alunas que, enxergando a Universidade como ambiente de discriminação e exclusão, se sentem cada vez menos incentivadas a dela fazer parte. E estando o ambiente acadêmico contaminado por valores que não refletem respeito às mulheres - sendo um agravante o fato disso não estar necessariamente explícito nas interações -, a atuação de profissionais que futuramente assumirão posições-chave na escala de poder e tomada de decisão será diretamente influenciada de forma negativa.

Diante desse quadro, em 2015 um grupo de alunas de Graduação e de PósGraduação iniciou uma reflexão conjunta sobre o que acreditavam no início serem suas inquietações pessoais acerca do silenciamento acadêmico feminino, formando o Grupo de Pesquisa e Estudo de Inclusão na Academia - GPEIA. A partir dos dados de campo levantados pelas pesquisadoras do GPEIA e posteriormente publicados por meio da obra Interações de gênero nas salas de aula da Faculdade de Direito da USP: um currículo oculto?, observa-se que, se as alunas iniciam a graduação em Direito autoconfiantes, tal atitude acaba por mudar, antes da conclusão do curso, para uma postura silenciada e insegura (durante o curso, a aluna é sistematicamente interrompida, sua opinião não é levada em conta, não se sente confortável para participar da discussão como sentem os homens, é apresentada a uma bibliografia composta predominantemente por autores homens, numa aula comandada por um homem). Como resultado desse processo, há no curso de Direito um movimento de "invisibilização" do gênero feminino e uma naturalização do masculino.

Com as docentes ocorre fenômeno semelhante, sendo a forma como são vistas pelos próprios discentes reveladora da inequidade de gênero. Assim, por exemplo, enquanto os docentes homens são vistos como seres complexos, integrais, as mulheres docentes são vistas como seres mais planos, a partir dos estereótipos de "mãe" (afetuosa) ou "megera" (rígida). ${ }^{28}$

Em suma, a investigação coordenada pela professora Sheila Christina Neder Cerezetti identificou as dinâmicas de gênero nas relações entre os(as) alunos(as) e entre estes(as) e os(as) docentes durante o curso de Graduação, evidenciando que

$27 \quad$ Sobre as dificuldades e desafios das mulheres na carreira docente junto à Faculdade de Direito da USP, é especialmente interessante o conjunto de relatos individuais registrados no âmbito do Projeto A mulher na universidade: foco na docência, desenvolvido pelo Movimento Resgate Arcadas em 2014.

28 NEDER CEREZETTI, Sheila Christina et al. Interações de gênero nas salas de aula da Faculdade de Direito da USP: um currículo oculto? São Paulo, Cátedra UNESCO de Direito à Educação/Universidade de São Paulo (USP), 2019. Disponível em: https://unesdoc.unesco.org/ark:/48223/pf0000367420. locale=en. Acesso em: 29 mar. 2021. 
a naturalização da autoridade e da presença masculina na docência contrasta com o estranhamento e reconhecimento do feminino. A pesquisa revelou, ainda, que as sutilezas nas diferenças de comportamento em relação a homens e mulheres na sala de aula caracterizam um marcador de gênero oculto, o que torna a inequidade de gênero mais difícil de ser percebida e enfrentada. ${ }^{29}$

A mencionada pesquisa realizada no âmbito da Graduação tem como um de seus méritos tornar visível o problema da inequidade de gênero no âmbito do ensino jurídico, permitindo avançar num debate mais consciente e qualificado. Da mesma forma, os resultados atingidos pelas pesquisadoras do GPEIA inspiraram novas investigações, agora no âmbito da Pós-Graduação, com resultados ainda parciais, mas bastante similares. ${ }^{30}$

O contexto atual da Pós-Graduação parece ser ainda mais propício à inequidade de gênero, estabelecendo-se dinâmicas de exclusão que se retroalimentam e que são performadas tanto por discentes quanto por docentes, seja em razão do menor número de alunos em sala de aula, seja diante do maior contato direto dos alunos com os docentes. De fato, a presença de um grupo relativamente pequeno de discentes (cerca de 20 alunos) matriculados em determinada disciplina tende a exigir mais participação ativa durante as aulas e atividades de seminário, tornando as disputas de fala e as manifestações de violência de gênero mais diretas e personalizadas, o que leva as alunas a um quadro de maior exposição e insegurança. Assim, essas alunas não raras vezes são incentivadas a silenciar, submetendo-se à hegemonia do discurso masculino, principalmente em determinadas áreas de concentração, ainda consideradas como território exclusivo dos homens (assim, por exemplo, a área de Direito do Trabalho e da Seguridade Social, que na Faculdade de Direito da USP conta apenas com docentes homens). De outro lado, o vínculo direto estabelecido entre aluna e orientador é apto a gerar dinâmicas de gênero disfuncionais a partir de preconceitos e estereótipos que podem contaminar a avaliação da capacidade acadêmica da mulher e, inclusive, gerar episódios de sexismo.

Na mesma linha, considerando que a frequência ao curso de Pós-Graduação muitas vezes coincide com o período em que a aluna inicia sua vida familiar, surgem especiais dificuldades e desafios de gênero relacionados aos papéis sociais atribuídos às mulheres em relação ao casamento/união afetiva e à maternidade. Divididas entre o que socialmente se espera delas como esposas, companheiras, cuidadoras e/ou mães e as atividades acadêmicas que devem desempenhar no âmbito da Pós-Graduação, as alunas

\footnotetext{
29 Idem, ibidem.

30 Nesse sentido, destaca-se a investigação atualmente em curso sobre as percepções e desafios da equidade de gênero das alunas do Programa de Pós-Graduação da Faculdade de Direito da USP, sob a coordenação da professora Susana Henriques da Costa. O respectivo relatório ainda pende de publicação.
} 
estão sujeitas a cobranças e manifestações de violência de gênero no plano simbólico que podem acarretar, inclusive, o abandono do curso ou sua conclusão de forma pouco satisfatória. $^{31}$

É importante observar que em todas as hipóteses apontadas o marcador de gênero frequentemente não é percebido nas interações acadêmicas. Nesse contexto, descortina-se a existência de um "currículo oculto", compreendendo padrões de comportamentos, normas sociais, expectativas e visões de mundo que reproduzem relações de poder, reforçam estereótipos e dinâmicas de gênero socialmente estabelecidas e impactam o processo de ensino-aprendizagem. ${ }^{32}$

O viés de julgamento implícito (inconsciente ou não percebido) relacionado à esfera acadêmica é em geral associado a estereótipos de baixo rendimento construídos socialmente e exerce fortes influências nas avaliações e julgamentos de mulheres. Assim, tais estereótipos transmitidos repetidamente por meio de vários canais de informação induzem crenças que serão utilizadas para organizar e categorizar socialmente o mundo, fazendo com que mesmo as pessoas que conscientemente acreditam e defendem princípios de justiça e não discriminação possam ter vieses implícitos que afetam imperceptivelmente seu julgamento. Diante de tal cenário de invisibilidade e de ambiguidades, faz-se necessário refletir sobre uma formação de gênero, que discuta o problema, e não o oculte ou transfira para a esfera individual.

3. Medidas possíveis para a promoção da equidade de gênero no âmbito acadêmico

Em uma sociedade estruturalmente patriarcal e machista, é papel da Academia mostrar que as relações podem e devem ser diferentes, formando alunas e alunos para uma experiência mais plural sobre as profissões jurídicas e a aplicação concreta do Direito. A maior missão docente consiste, sob essa perspectiva, em conduzir a um caminho de constante reflexão, permitindo não só conhecer a realidade, mas também elaborar mecanismos para superar estereótipos e preconceitos. Nesse sentido, conforme aponta bell hooks, a prática do diálogo corresponde a um dos meios mais simples para que professores, alunos e pesquisadores críticos possam começar a cruzar as fronteiras e transgredir as barreiras erguidas pelo gênero. ${ }^{33}$

31 Nesse sentido, não é raro que as alunas cheguem a pedir desculpas a seus professores e orientadores pelo fato de terem engravidado, como se a gravidez pudesse ser considerada um empecilho ou constrangimento para o curso de Pós-Graduação.

32 Cf. NEDER CEREZETTI, Sheila Christina et al. Interações de gênero nas salas de aula da Faculdade de Direito da USP, cit., p. 115.

33 HOOKS, bell. Ensinando a transgredir: a educação como prática de liberdade. Trad. Marcelo Brandão Cipolla. São Paulo: Martins Fontes, 2013, p. 174. 
A fim de que o ensino jurídico possa servir como instrumento para promover equidade de gênero, é necessário, em primeiro lugar, que os espaços acadêmicos sejam ocupados por diferentes visões, permitindo uma construção democrática. Para isso, algumas medidas soam promissoras, ensejando um reequilíbrio na dinâmica das relações entre discentes e entre esses e o corpo docente. Dentre elas, sem dúvida está o incentivo à maior participação feminina nas aulas e atividades acadêmicas.

Evidente que a maior participação acadêmica das alunas depende de uma reestruturação metodológica das atividades, a partir de uma pedagogia não discriminatória que comece a tratar expressamente das questões de gênero em sala de aula, ${ }^{34}$ de forma a construir uma consciência geral sobre o tema.

De outra parte, a maior representação das mulheres no Direito está condicionada a uma maior representatividade feminina no próprio ensino jurídico. Mais docentes mulheres induzem, como modelo, a um maior engajamento feminino nas atividades acadêmicas, a partir da demonstração de que as alunas podem e devem ocupar seus espaços na Universidade, da mesma forma que os alunos tradicionalmente o fazem. ${ }^{35}$ No mesmo sentido, a adoção de bibliografia mais feminina (na atualidade a bibliografia das disciplinas frequentemente é composta quase que exclusivamente por autores homens), a presença de mulheres em posições decisórias e a paridade de gênero em bancas examinadoras ${ }^{36}$ e em eventos científicos ${ }^{37}$ são medidas fundamentais na perspectiva da representatividade e podem influenciar no sentimento de pertencimento acadêmico, estimulando a participação ativa.

De qualquer modo, o tratamento das questões de gênero não pode ser considerado de forma abstrata e uniforme, em razão das interseccionalidades envolvidas. Assim, a valorização das diversidades é fundamental neste campo, revelando-se

34 Conforme a pesquisa de campo realizada pelo GPEIA, a abordagem expressa de questões de gênero em sala de aula gerou impacto positivo nas interações entre discente e entre estes e os docentes. Cf. NEDER CEREZETTI, Sheila Christina et al. Interações de gênero nas salas de aula da Faculdade de Direito da USP, cit., p. 111.

35 O aumento das mulheres na carreira acadêmica pressupõe, porém, uma revisão das regras e dinâmicas dos concursos de ingresso e progressão funcional, tomando em consideração as questões de gênero. Assim, por exemplo, tem-se como questões sujeitas à especial reflexão a duração e intervalo entre as provas, a composição paritária quanto ao gênero das bancas examinadoras e prazos diferenciados em caso de candidata gestante ou em período de amamentação.

36 No novo Regimento do Programa de Pós-Graduação da Faculdade de Direito da USP, recentemente aprovado pela Congregação, há previsão expressa sobre a paridade de gênero nas bancas examinadoras. O exemplo do mencionado diploma normativo serviu como modelo para a elaboração da Diretriz pela Pró-Reitoria de Pós-Graduação da Universidade de São Paulo versando sobre equidade de gênero e de raça-etnia, bem como para inclusão de pessoas com deficiência nas comissões julgadoras das defesas de dissertações e teses, atualmente vigente e aplicável a todos os Programas de Pós-Graduação da USP.

37 Nesse sentido, destaca-se positivamente a portaria 09/2020, do Diretor da Faculdade de Direito da USP, que estabelece normas e critérios para promover a diversidade na composição dos participantes de eventos acadêmicos a serem realizados no âmbito da instituição de ensino. 
especialmente positiva, inclusive, a busca de diálogo entre as diferentes Universidades e seus respectivos Programas de Pós-Graduação, haja vista a riqueza e variedade de experiências vivenciadas por cada qual em matéria de gênero.

Em relação às violências concretas ainda enfrentadas pelas mulheres no ambiente acadêmico, uma medida necessária à equidade de gênero é a criação de ouvidorias de gênero pelas Universidades,$^{38}$ com o fim de receber e processar denúncias de assédio de gênero, prática de atos potencialmente preconceituosos ou sexistas, agressões de conotação sexual ou sexista bem como qualquer manifestação de discriminação relacionada ao gênero ou à orientação sexual. Para além de eventual encaminhamento sancionatório, a atividade de tais ouvidorias deve voltar-se fundamentalmente ao diálogo sobre esses temas, com função pedagógica de conscientização em matéria de gênero.

Finalmente, uma formação acadêmica atenta às questões de gênero depende da produção e divulgação de conhecimento específico sobre o tema. Nesse sentido, é interessante o exemplo desenvolvido na Faculdade de Direito da USP, a partir do ano de 2020, por meio de disciplinas de Graduação e de Pós-Graduação sobre "Direito e Equidade de Gênero", sob coordenação da Professora Nina Beatriz Stocco Ranieri, no âmbito da Cátedra Unesco de Direito à Educação - USP. Em ambos os níveis acadêmicos, são desenvolvidas atividades interdepartamentais voltadas à formação em gênero aplicada às diversas áreas jurídicas, ${ }^{39}$ envolvendo a participação ativa de alunas e alunos que, ao final, são incentivados a produzir pesquisas e materiais de divulgação sobre o tema. ${ }^{40}$ Sobre tais experiências, o resultado mais interessante talvez seja o processo de conscientização operado no próprio corpo docente da Faculdade de Direito, que, por meio da participação nas atividades desenvolvidas, se dá conta de questões e desafios até então invisibilizados pelo discurso masculino dominante.

O desenvolvimento de disciplinas específicas sobre equidade de gênero não exclui, porém, a necessidade de integrar reflexões de gênero de forma transversal no currículo acadêmico em geral, levando a reflexão para todas as disciplinas. Apenas a partir dessa perspectiva ampla e transversal de gênero no ensino jurídico é possível o desenvolvimento de uma metodologia distinta da teoria do Direito, operando transformações concretas na formação dos alunos.

38 Em novembro de 2018, por meio da Portaria GDI n. 49/2018, foi criada a Ouvidoria de Gênero na Faculdade de Direito da USP.

39 As aulas da Disciplina "Equidade de Gênero e Direito", ministradas no segundo semestre de 2020 aos alunos de Graduação da Faculdade de Direito da USP, estão disponíveis ao público por meio do canal eletrônico da Faculdade: https://www.youtube.com/watch?v=U11nps4vrqA.

40 Os alunos ingressantes na Faculdade de Direito da USP em 2021 receberão, como parte do material de recepção acadêmica, cartilhas sobre equidade de gênero produzidas no âmbito da disciplina "Direito e Equidade de Gênero". O material completo está disponível em: https://linktr.ee/equiddgenerofdusp. Acesso em: 30 mar. 2021. 
Sob uma perspectiva distinta, de nada adianta promover uma formação em gênero se a estrutura universitária não levar em conta as diferenças e necessidades femininas. Por isso, cabe às Faculdades de Direito e seus respectivos Programas de Pós-Graduação proceder a uma ampla revisão normativa, a fim de identificar e corrigir hipóteses que desfavoreçam as alunas em razão de gênero. Não se pretende com isso afirmar que as normas dos Programas de Pós-Graduação sejam deliberadamente voltadas a gerar prejuízos às mulheres. $\mathrm{Na}$ verdade, tais prejuízos decorrem da ausência da valoração das normas, no momento de sua elaboração, sob uma perspectiva distinta da masculina (afinal as normas em geral ainda são elaboradas por homens e para homens).

Sobre esse tema, pode-se mencionar a título ilustrativo o caso do regimento do Programa de Pós-Graduação da Faculdade de Direito da USP, ao tratar da licença-maternidade como direito garantido às alunas. Conforme a redação original do diploma legal, por ocasião do nascimento de seu filho ou filha, a aluna passa a fazer jus à licença-maternidade, pelo prazo de seis meses, com o fim de possibilitar o exercício das funções maternas, sem prejuízo ao desenvolvimento das atividades acadêmicas, que têm seu prazo postergado. Ocorre que, caso o parto ocorra no meio do semestre letivo, o reconhecimento da licença-maternidade pelo Programa de Pós-Graduação acaba concretamente impedindo o aproveitamento de disciplinas em curso (mesmo que tenha havido o cumprimento dos requisitos materiais para a aprovação da aluna), bem como a matrícula em disciplinas após seu término, caso este ocorra no meio do semestre letivo seguinte, fora do período normal de matrícula dos alunos.

Diante da situação esdrúxula imposta pela norma, a implicar em determinados casos a impossibilidade de cursar disciplinas em plena vigência do prazo de conclusão do curso de mestrado ou doutorado, grande parte das alunas acaba abrindo mão da licença-maternidade, a fim de não perder os créditos em disciplinas necessários à conclusão exitosa do curso. Outras alunas, ainda, chegam a desenvolver quadros de depressão/ansiedade, ou terminam mesmo por desistir do curso de Pós-Graduação, diante da grande pressão a que se veem submetidas. Essa hipótese foi recentemente debatida pela Comissão de Pós-Graduação da Faculdade de Direito, que decidiu pela possibilidade de reconhecimento dos créditos cursados, bem como de matrícula extemporânea em disciplinas a alunas que cumpram os requisitos necessários, sem prejuízo do reconhecimento da licença-maternidade.

É importante ressaltar, portanto, que a equidade de gênero no ensino jurídico e, consequentemente, a maior representação feminina no Direito só poderão ser atingidas por meio de ações afirmativas e reflexões de diferentes níveis e escopos que abranjam mais do que o mero incentivo ao ingresso ou permanência no Programa de PósGraduação, compreendendo também a necessidade de uma educação de gênero. Apenas assim abrir-se-á um novo espaço de participação acadêmica feminina, a influenciar as 
futuras gerações, cumprindo a norma e o espírito republicano da Constituição de 1988 e do Estado Democrático de Direito.

Conclusão

O Direito ainda é um território masculino, marcado por preconceitos e estereótipos de gênero que levam à discriminação das mulheres. Equidade de gênero só se conquista com a promoção de uma educação de gênero, especialmente relevante no contexto dos Programas de Pós-Graduação em Direito, responsáveis pela formação de profissionais que assumirão posições-chave no ensino jurídico.

Partindo do papel estratégico dos Programas de Pós-Graduação em Direito como espaço de reflexão sobre discussões até então silenciadas no âmbito jurídico, a maior representatividade feminina nessa esfera é fundamental, no sentido de garantir uma reflexão verdadeira. Nesse sentido, é justamente nas pesquisas sobre mulheres, relações de gênero e violência que se encontram, a partir da década de 1970, os contornos da crítica feminista ao Direito, o que só foi e segue sendo possível graças ao trabalho de mulheres que resistem às dificuldades do ambiente acadêmico para promover uma reflexão crítica sobre o saber jurídico.

Isso não significa excluir os homens do processo de reflexão sobre a inequidade de gênero como problema social relevante e de reconstrução crítica do ensino jurídico, sob a perspectiva de gênero. Para o êxito de tal desafio, é necessário que homens e mulheres trabalhem juntos, com consciência sobre seu poder de transformação.

Apenas desse modo será possível construir um ensino jurídico que privilegie a participação das alunas e alunos no processo de ensino-aprendizagem, de forma a permitir a superação de um Direito "neutro" excludente e, assim, a compreensão das interações sociais a partir das diferenças, inclusive em relação ao gênero.

O debate está apenas começando e existem vários desafios a serem enfrentados nos próximos anos. De toda forma, este parece já ser um caminho sem volta.

\section{Referências}

ADORNO, Sérgio. Os aprendizes do poder. São Paulo: Paz e Terra, 1988.

ALMEIDA, Maria Clara D’Avila. Gênero, violência e subversão: o ensino jurídico como prática de liberdade. Trabalho de Conclusão de Curso, Faculdade de Ciências Jurídicas e Sociais do Centro Universitário de Brasília - UniCEUB. Brasília, 2016.

ANDRADE, Mailô de Menezes Vieira. Ela não mereceu ser estuprada. A cultura do estupro nos casos penais. Rio de Janeiro: Lumen Juris, 2018. 
BERTOLIN, Patrícia Tuma Martins. Feminização da advocacia e ascensão das mulheres nas sociedades de advogados. Cadernos de Pesquisa. 2017, v. 47, n. 163, p. 25. Disponível em: https:// www.scielo.br/scielo.php?pid=S0100-15742017000100016\&script=sci_abstract\&tlng=pt. Acesso em: 2 abr. 2021.

BOKEK-COHEN, Ya'arit; DAVIDOWITZ, Nitza. Beauty and teaching evaluation: a comparison between female and male college professors. Problems of Education in the 21st Century, v. 7, 2008. Disponível em http://www.scientiasocialis.lt/pec/files/pdf/Bokek-Cohen.pdf.

BONELLI, Maria da Gloria. Docência do direito: fragmentação institucional, gênero e interseccionalidade. Cadernos de Pesquisa. 2017, v. 47, n. 163.

CAMPOS, Isabelle Oglouyan de. Mulheres na Academia: Desigualdades de Gênero no Corpo Docente da Faculdade de Direito da Universidade de São Paulo. São Paulo: Cátedra UNESCO de Direito à Educação/Universidade de São Paulo, 2021, p. 21-22. Disponível em: https://unesdoc. unesco.org/ark:/48223/pf0000376046.

CRENSHAW, Kimberlé Williams. Documento para o encontro de especialistas em aspectos da discriminação racial relativos ao gênero. Estudos feministas, Ano 10, $1^{\circ}$ semestre de 2002.

FACIO, Alda. Hacia outra teoria crítica del derecho. In: FACIO, A.; FRIES, Lorena (coord.). Género y derecho. Santiago de Chile: LOM Ediciones, 1999.

HOOKS, bell. Ensinando a transgredir: a educação como prática de liberdade. Trad. Marcelo Brandão Cipolla. São Paulo: Martins Fontes, 2013.

LEMAITRE RIPOLL, Julieta. El feminismo en la enseñanza del derecho en los Estados Unidos: estrategias para América Latina. Academia: Revista sobre enseñanza del Derecho de Buenos Aires, Buenos Aires, ano 3, n. 6, 2005. Disponível em: https://revistas-colaboracion.juridicas.unam.mx/ index.php/revista-ensenianza-derecho/article/view/33855.

MACKINNON, Catherine A. Mainstreaming feminism in legal education. Journal of Legal Education, v. 53, n. 2, 2003.

MOSCHKOVICH, Marília Bárbara Fernandes Garcia. Teto de vidro ou paredes de fogo? Um estudo sobre gênero na carreira acadêmica e o caso da UNICAMP. 2013. Dissertação de Mestrado - Universidade Estadual de Campinas, Faculdade de Educação, Campinas, SP. Disponível em: http://www.repositorio.unicamp.br/REPOSIP/251113.

MOVIMENTO RESGATE ARCADAS. Mulheres e carreira: docência em foco. 2014. Disponível em: https://www.youtube.com/watch?v=NWTmsOVvBYA.

NEDER CEREZETTI, Sheila Christina et al. Interações de gênero nas salas de aula da Faculdade de Direito da USP: um currículo oculto?, São Paulo, Cátedra UNESCO de Direito à Educação / Universidade de São Paulo (USP), 2019. Disponível em: https://unesdoc.unesco.org/ark:/48223/ pf0000367420.locale $=$ en. 
PIMENTEL, Silvia et al. Recuperando a memória: a atuação das feministas na conquista dos direitos das mulheres e os desafios atuais para assegurar os direitos conquistados. In: Vv. Aa. Tecendo fios das críticas feministas ao direito no Brasil. Rev. Técnica Fabiana Severi e Myllena Calasans de Matos. Ribeirão Preto: FDRP/USP, 2019.

PIMENTEL, Silvia; SCHRITZMEYER, Ana Lúcia P.; PANDJIARJIAN, Valéria. Estupro: crime ou "cortesia"? Abordagem sociojurídica de gênero. Porto Alegre: Fabris, 1998.

SCOTT, Joan W. Gênero: uma categoria útil de análise histórica. Trad. Guacira Lopes Louro, ver. Tomaz Tadeu da Silva. Educação \& Realidade, Porto Alegre, v. 20, n. 2, jul./dez. 1995.

SEVERI, Fabiana Cristina; CAMPOS, Carmen Hein. Violence against women and the feminist critique of law: a brief analysis of Brazilian academic production. Revista Direito e Práxis, Rio de Janeiro, v. 10, n. 2, 2019.

VENÂNCIO FILHO, Alberto. Das arcadas ao bacharelismo: cento e cinquenta anos de ensino jurídico no Brasil. Rio de Janeiro: Perspectiva, 1977.

VENTURINI, Anna Carolina. Ações afirmativas para pós-graduação: desenho e desafios da política pública. $41^{\circ}$ Encontro Anual da ANPOCS, 2017.

WU, Alice. Gender Stereotype in Academia: Evidence from Economics Job Market Rumors Forum, Working Papers 2017-09, Princeton University, Woodrow Wilson School of Public and International Affairs, Center for Health and Wellbeing, 2017. Disponível em: https://ideas.repec. org/p/pri/cheawb/2017-09.html. 